\title{
About the detection of urea in the interstellar medium: the energetic aspect
}

\author{
I. Fourré ${ }^{1,2}$, L. Rosset ${ }^{1,2}$, H. Chevreau ${ }^{1,2}$, and Y. Ellinger ${ }^{1,2}$ \\ 1 Sorbonne Universités, UPMC Univ. Paris 06, UMR 7616, Laboratoire de Chimie Théorique, 75252 Paris Cedex 05, France \\ 2 CNRS, UMR 7616, Laboratoire de Chimie Théorique, 75252 Paris Cedex 05, France \\ e-mail: ellinger@lct.jussieu.fr
}

Received 10 October 2015 / Accepted 22 January 2016

\begin{abstract}
Context. The results of an observational search for gas phase urea, $\left(\mathrm{NH}_{2}\right)_{2} \mathrm{CO}$ toward the Sgr B2-LMH region, have been reported recently. In spite of strong presumptions, whether it is urea or another species (for example an isomer) seems to remain a pending question.

Aims. In this note, we consider the energetic aspect of this would-be detection by addressing the relative stabilities of the 22 isomers that can possibly be formed with the $\mathrm{CH}_{4} \mathrm{~N}_{2} \mathrm{O}$ set of atoms. By extension, we also consider the 22 sulphur analogues of $\mathrm{CH}_{4} \mathrm{~N}_{2} \mathrm{~S}$ chemical formula.

Methods. The question was first addressed by means of quantum density functional theory (DFT) simulations. The hybrid B3LYP functional was used throughout. The geometries of the 44 molecules part of this survey were fully optimized and verified to be real minima by vibrational analysis. The lowest isomers found this way were then reconsidered in higher level post Hartree-Fock MP2 and coupled cluster CCSD and CCSD(T) calculations to derive more accurate energy differences and dipole moments, whose knowledge is crucial for interpreting micro- and millimetre-wave spectra.

Results. We found that urea and thio-urea are the most stable compounds in their respective families. The closest isomers on the energy scale are the iminol tautomeric forms, $\mathrm{HN}=\mathrm{COH}-\mathrm{NH}_{2}$ and $\mathrm{HN}=\mathrm{CSH}-\mathrm{NH}_{2}$, whose rotational constants and dipole moments have also been determined.

Conclusions. That urea is the lowest energy isomer possibly formed is a strong argument making the detection of this species more than probable. After formamide and acetamide, this result confirms the greatest stability of the $-[\mathrm{NH}-\mathrm{C}=\mathrm{O}]-$ linkage, underlining the interest of the minimum energy criterion as a tool for the primary search of target molecules. Additionally, thio-urea should the analogue to search for.
\end{abstract}

Key words. astrobiology - astrochemistry - molecular data - molecular processes - ISM: abundances - ISM: molecules

\section{Introduction}

It has been recently proposed that urea, the well known molecular corner stone in the search for the origin of life, is the source of some weak mm-wave emission lines in the spectrum of the Sgr B2-LMH region (Remijan et al. 2014). However, citing the authors of this study, "... the spectral complexity of both the $\left(\mathrm{NH}_{2}\right)_{2} \mathrm{CO}$ and of Sgr B2-LMH makes the definitive identification of this molecule challenging". It is not the first time that detection of urea poses a problem. Since its identification in the Murchison meteorite (Hayatsu et al. 1975) and the discovery of formamide, $\mathrm{H}_{2} \mathrm{NCHO}$ (Rubin et al. 1971), the peptide linkage $-[\mathrm{NH}-\mathrm{C}=\mathrm{O}]-$ has been the centre of the most attention because of its participation in biological systems, particularly in amino acids. It has been identified in acetamide, $\mathrm{H}_{2} \mathrm{NCOCH}_{3}$ (Hollis et al. 2006), and concerning urea, was predicted to be in detectable abundances by chemical models (Garrod et al. 2008). In spite of the model prediction and laboratory work (Duvernay et al. 2005) in a cryogenic matrix designed to reproduce the interstellar environment, only a tentative detection was reported (Raunier et al. 2004) from the analysis of icy dust grain spectra towards the protostellar source NGC 7538 IRS9.

In fact urea, has been known since 1828, the year when Wöhler made the synthesis by making silver cyanate react with ammonium chloride (Wöhler 1828). Neither he nor his master,
Berzelius, (as shown by their exchange of letters) realized the fundamental impact that this reaction that leads to an organic product of animal metabolism from purely mineral substances would have in the future. The most widely held belief at that time was that "vital" compounds, i.e. those that had an animal origin could only be produced by living organisms. It was a century later (Haldane 1929) that the first modern theory of the primary steps of emerging life was formulated. These pioneering works are often occulted, and the scientific investigation into the origin of life is generally dated to the fifties with the experiments conducted by Miller's group (Miller 1953; Miller \& Urey 1959). Has urea been formed in the gas phase or with the mediation of interstellar dust?

The mechanism of gas phase formation is still not understood. The possibility of it being formed in or on icy interstellar grains again raises the question of the adsorption of the molecule on the solid surface, meaning that the abundance observed might be much lower than what is really synthesized. The question has been addressed by Tsipis \& Karapidis (2003). These authors found that important activation barriers oppose the gas phase process at $298 \mathrm{~K}$. With one or two molecules of $\mathrm{H}_{2} \mathrm{O}$ or $\mathrm{NH}_{3}$ properly placed and optimized to mimic reactivity in liquid or ices, the calculated activation energies decreased significantly. 
These interesting results may be adapted to laboratory chemistry at room temperature but are not relevant to interstellar chemistry where there is no liquid phase available. In addition, ices are solids of infinite dimensions that cannot be properly described by one or two molecules. The important result that we suppose can be generalized to all environments is that the lower energy paths go through a tautomeric form of urea. At all events, the observations of urea in gas phase reported by Remijan et al. (2014) are of utmost importance. In an earlier article, we suggested guidelines for "optimizing" the hunt of new species in the interstellar medium (ISM) by identifying the potentially more abundant isomers of a given chemical formula, i.e. those of lowest energies (Lattelais et al. 2010). We called this the minimum energy principle or MEP (Lattelais et al. 2009).

Is the present detection of urea compatible with the minimum energy criterion? The answer is presented in this note in which we report computations of the thermodynamic stability of $\left(\mathrm{NH}_{2}\right)_{2} \mathrm{CO}$ compared to its isomers. By extension we also report the results of the same study on the closest analogue, thio-urea in view of possible search in the ISM. The methods employed are presented in Sect. 2, results are detailed in Sect. 3, and a discussion follows in Sect. 4.

\section{Computational background}

In view of the large number of systems to consider, a multi-step strategy was developed to reach a compromise between the level of theory and the computational requirements.

The first task was to determine all the isomers to consider. From a given molecular formula, the Scifinder data base ${ }^{1}$ provides only substances already archived with a CAS registry number, which is a unique numeric identifier in the chemical abstract service file. Considering that our goal was to classify the whole set of possible isomers for urea and thiourea on an energetic scale, we employed a code specifically designed to build molecular structures knowing the raw chemical formula. Briefly, the molecule is considered as a weighted graph with vertexes corresponding to atoms and edges corresponding to bonds. Each of these edges is associated to weights corresponding to formal bond orders of 1, 2, 3, etc. for single, double, and triple bonds, etc., respectively (Rouvray 1974; Bonchev \& Rouvray 1991). The purpose of the isomer generator is then to enumerate all possible graphs so as to verify the predefined chemical valences for each atom, i.e. a specified vertex degree in the graph. Duplicate structures are eliminated by using an isomorphic graph algorithm (McKay \& Piperno 2014) for comparing any new structure to those already classified in the growing list of isomers.

With the different isomers known, a first screening was made using density functional theory (DFT) within the hybrid B3LYP formalism (Becke 1993; Lee et al. 1988), coupled to the standard 6-31G(d,p) basis set. For a comprehensive presentation of DFT methods and their application to reproduce the structural properties, energies, and spectroscopic parameters (vibration frequencies, dipole moments, etc.) of organic molecules, the reader should refer to Lee \& Scuseria (1995) and Koch \& Holthausen (2001).

Each structure, fully optimized, was verified to be an energy minimum by vibrational analysis. All 22 isomers, whose Lewis structures are represented in Table 1, were studied for both the urea and thiourea families. For each isomer, several conformers (differing by their $\mathrm{Z}$ or E conformation, the orientation of the $\mathrm{OH}$ or $\mathrm{NH}_{2}$ groups, etc.) were optimized. No constraint was enforced

1 See e.g. http://www. cas.org/products/scifinder on any geometry, in particular that of planarity. Only the relative energies and dipole moments of the most stable ones are reported in the tables, except for urea, for which two conformers, which are very close in energy, might co-exist.

To get more accurate answers to the energetics problem, the relative stabilities of the first six isomers were recomputed at higher levels of theory. First, these isomers were fully reoptimized, and their zero point vibrational energy (ZPE) calculated, at the Möller-Plesset second-order perturbation theory (MP2). A clear introduction to post Hartree-Fock theories can be found in Szabo \& Ostlund (1996). The "correlation-consistent" cc-pVTZ basis set was used (Dunning 1989), which is optimized with correlated atomic wavefunctions and thus particularly adapted to post Hartree-Fock calculations. Then, taking these MP2/ccpVTZ geometries as starting points, single-point energy calculations were carried out at the highly correlated CCSD/cc-pVTZ and $\operatorname{CCSD}(\mathrm{T}) / \mathrm{cc}-\mathrm{pVTZ}$ levels of theory ${ }^{2}$.

All the reported energy differences include ZPE correction: in the case of B3LYP and MP2 calculations, it was extracted from frequencies calculations at the same level, whereas the MP2 value was used at the CCSD and CCSD(T) levels. We have verified that including entropic terms to determine the Gibbs free energies of formation at the temperature estimated for the Sgr B2-LMH region considered here has a marginal impact on the values of the energy differences. The dipole moments were also recalculated at the MP2/cc-pVTZ and CCSD/cc-pVTZ levels. They were refined ultimately at the CCSD level by using an extended aug-cc-pVTZ basis set ${ }^{3}$ (Tables 2 and 3 ).

All the calculations were performed using methods and basis sets as implemented in the GAUSSIAN 09 package (Frisch et al. 2009).

\section{Results}

Among the twenty-two isomers corresponding to the $\mathrm{CH}_{4} \mathrm{~N}_{2} \mathrm{X}$ $(\mathrm{X}=\mathrm{O}$ or $\mathrm{S}$ ) raw formula, thirteen have a linear backbone of the four heavy atoms, and two are branched molecules (which are the most stable isomers for each family, see below). Seven cycles can be formed (five 3-atom cycles and two 4-atom ones), but corresponding to the most energetic species (Table 1). We discuss first the results concerning the urea family $(X=O)$ and then the ones of the thiourea family $(X=S)$.

\section{1. $\mathrm{CH}_{4} \mathrm{~N}_{2} \mathrm{O}$ isomers}

A wide variety of chemical substances can be built from the $\mathrm{CH}_{4} \mathrm{~N}_{2} \mathrm{O}$ set of atoms: amides, imines, hydrazides, diazenes, alcools, and cyclic species. Our computations give urea, $\left(\mathrm{NH}_{2}\right)_{2} \mathrm{CO}$, as the most stable system at the B3LYP/6-31G(d,p) level (Table 1), as well as at the MP2/ccpVTZ and higher levels of theory (Table 2). The structure of isolated urea has long been the subject of much debate. It has been recently reviewed by Inostroza \& Senent (2012), who studied the large amplitude vibrations of this molecule. In agreement with previous

\footnotetext{
2 In these methods, the electronic correlation is calculated by including the interaction energy between the ground state and the excited states obtained by single and double excitations for CCSD and by single, double, and triple excitations for $\operatorname{CCSD}(\mathrm{T})$ (the triple excitations being treated in a perturbative way).

3 It should be noted that dipole moments extracted from a CCSD calculation are actually calculated using a quadratic configuration interaction procedure based on all possible single and double excitations from the ground state.
} 
Table 1. Computed relative stabilities $(\mathrm{kcal} / \mathrm{mol})$ and dipole moments (Debye) of urea $(X=O)$ and thiourea $(X=S)$ isomers at the B3LYP/6$31 \mathrm{G}(\mathrm{d}, \mathrm{p})$ level of theory.

\begin{tabular}{|c|c|c|c|c|c|}
\hline \multirow{2}{*}{$\begin{array}{l}\text { Serial } \\
\#\end{array}$} & \multirow{2}{*}{$\begin{array}{c}\text { Isomer } \\
\text { structure }\end{array}$} & \multirow{2}{*}{$\begin{array}{c}\text { Urea } \\
\Delta E\end{array}$} & \multicolumn{3}{|c|}{ Thiourea } \\
\hline & & & $\mu$ & $\Delta E$ & $\mu$ \\
\hline $1\left(C_{2}\right)$ & & 0.0 & 3.53 & 0.0 & 5.2 \\
\hline $1\left(C_{\mathrm{S}}\right)$ & & 0.6 & 4.24 & - & - \\
\hline 2 & & 16.1 & 2.32 & 15.4 & 2.8 \\
\hline 3 & & 35.2 & 2.32 & 32.3 & 3.22 \\
\hline 4 & & 44.9 & 1.46 & 38.3 & 1.56 \\
\hline 5 & & 53.9 & 1.94 & 25.5 & 2.72 \\
\hline 6 & & 56.9 & 1.64 & 47.0 & 2.02 \\
\hline 7 & & 63.8 & 3.05 & 31.1 & 2.96 \\
\hline 8 & & 63.8 & 3.44 & 31.5 & 2.17 \\
\hline 9 & & 65.7 & 3.95 & 46.6 & 4.73 \\
\hline 10 & & 68.2 & 1.75 & 46.6 & 1.67 \\
\hline 11 & & 71.1 & 2.47 & 67.5 & 4.11 \\
\hline 12 & & 72.3 & 1.84 & 50.3 & 2.21 \\
\hline 13 & & 72.7 & 2.3 & 47.6 & 1.90 \\
\hline 14 & & 74.5 & 1.10 & 53.5 & 1.35 \\
\hline 15 & & 75.2 & 1.84 & 43.3 & 4.73 \\
\hline 16 & & 85.3 & 2.33 & 52.9 & 1.54 \\
\hline 17 & & 93.7 & 2.09 & 62.3 & 2.39 \\
\hline 18 & & 97.5 & 2.49 & 40.1 & 2.95 \\
\hline 19 & & 98.3 & 1.35 & 72.8 & 1.53 \\
\hline 20 & & 105.9 & 1.70 & 73.5 & 1.74 \\
\hline 21 & & 119.8 & 1.33 & 75.0 & 0.74 \\
\hline 22 & & 120.4 & 2.45 & 67.2 & 1.55 \\
\hline
\end{tabular}

calculations, these authors found two quasi-isoenergetic conformers, one of $C_{2}$ symmetry being slightly more stable than the one of $C_{\mathrm{s}}$ symmetry by $0.93 \mathrm{kcal} / \mathrm{mol}$ at the MP2/augccpVTZ level $(0.45 \mathrm{kcal} / \mathrm{mol}$ with ZPE included $)$. We reached the same conclusion, because the difference in energy between both conformers is $1.16 \mathrm{kcal} / \mathrm{mol}$ at the MP2/ccpVTZ level $(0.70 \mathrm{kcal} / \mathrm{mol}$ with ZPE included). Moreover, our fully optimized structures of both conformers agree with the calculations of Inostroza \& Senent (2012). With similar N-C=O connectivity, formamide $\mathrm{H}_{2} \mathrm{NCHO}$ and acetamide $\mathrm{H}_{2} \mathrm{NCOCH}_{3}$ are also the most stable systems that can be formed from the $\mathrm{CH}_{3} \mathrm{NO}$ and $\mathrm{C}_{2} \mathrm{H}_{5} \mathrm{NO}$ sets of atoms, respectively (Lattelais et al. 2010). All three molecules are now identified in the ISM.

The next isomer on the energy scale is the iminol tautomer carbamimidic acid, $\mathrm{HN}=\mathrm{COH}-\mathrm{NH}_{2}, 16 \mathrm{kcal} / \mathrm{mol}$ higher with a dipole moment of 2.3 Debye. It is noteworthy that the iminol tautomers of formamide and acetamide were only found $\sim 13 \mathrm{kcal} / \mathrm{mol}$ above the most stable isomers, but their dipole moment were lower (1 and 1.5 Debye, respectively); as a result, $\mathrm{HN}=\mathrm{COH}-\mathrm{NH}_{2}$ still represents a potential target in the same way as $\mathrm{CH}_{2}=\mathrm{CH}-\mathrm{OH}$, the first isomer of $\mathrm{CH}_{3} \mathrm{CHO}$ (Fourikis et al. 1974; Gilmore et al. 1976), at $\sim 10 \mathrm{kcal} / \mathrm{mol}$ on the energy scale that was identified twenty seven years later (Turner \& Apponi 2001). Isomers 3 (formohydrazide $\mathrm{NH}_{2} \mathrm{NHCHO}$ ) and 4 (methanehydrazonic acid $\mathrm{NH}_{2} \mathrm{~N}=\mathrm{CHOH}$ ), which are 34 and $45 \mathrm{kcal} / \mathrm{mol}$ respectively above urea, are also related by a amide-iminol tautomerism. The dipole moment of formohydrazide is almost equal to the one of carbamimidic acid (2.3 Debye). It should be noted that these first four isomers contain the NCO connectivity. Isomers 5 and 7 are the first ones with a ONCN connectivity within the urea family. They are both hydroxymethanimidamides at 54 and $64 \mathrm{kcal} / \mathrm{mol}$, respectively, on the energy scale, and their structures differ by the functional group undergoing the hydroxy substitution (the imino group for isomer $5 ; \mathrm{HON}=\mathrm{CHNH}_{2}$, and the amino one for isomer 7, $\mathrm{HON}$ $\mathrm{HCH}=\mathrm{NH}$. Isomer 5 with its $\mathrm{HON}=\mathrm{CHR}\left(\mathrm{R}=\mathrm{NH}_{2}\right)$ structure can be compared to isomer 3 of formamide $\mathrm{HON}=\mathrm{CH}_{2}(51 \mathrm{kcal} / \mathrm{mol}$ higher in energy than $\mathrm{NH}_{2}-\mathrm{CHO}$ ). However, the dipole moment of $\mathrm{HON}=\mathrm{CHNH}_{2}, 1.9$ Debye, is much larger than that of formaldoxime (0.2 Debye).

Isomer $6, \mathrm{NH}=\mathrm{NCH}_{2} \mathrm{OH}$, which is $57 \mathrm{kcal} / \mathrm{mol}$ above urea, is the first compound with a diazene bond ( $\mathrm{N}=\mathrm{N}$ double bond). Isomer $8, \mathrm{H}_{2} \mathrm{NOCH}=\mathrm{NH}$, is obtained from isomer 7 by exchanging the terminal oxygen atom and the nitrogen atom of the amino group. It has the same relative energy with respect to urea (64 kcal/mol), as well as a similar dipole moment (3.4 Debye). This is the last isomer with a NCO connectivity, whereas in isomers of formamide and acetamide, this connectivity does not occur at relative energies higher than 13 and $26 \mathrm{kcal} / \mathrm{mol}$ because of weaker molecular complexity.

As the first nitrous oxide isomer of urea, isomer 9, $\mathrm{CH}_{3} \mathrm{NHN}=\mathrm{O}(66 \mathrm{kcal} / \mathrm{mol}$ on the energy scale $)$, plays the same role as nitrosomethane $\mathrm{CH}_{3} \mathrm{~N}=\mathrm{O}(63 \mathrm{kcal} / \mathrm{mol}$ higher in energy than formamide) and nitrosoethane $(67 \mathrm{kcal} / \mathrm{mol}$ with respect to acetamide). However, its dipole moment is significantly larger (4.0 Debye compared to 2.5 Debye). Another isomer with a $\mathrm{N}=\mathrm{O}$ bond is found in 14 th position on the energy scale at $74.5 \mathrm{kcal} / \mathrm{mol}$. Isomer $10, \mathrm{CH}_{3} \mathrm{~N}=\mathrm{NOH}$, is the second species with a $\mathrm{N}=\mathrm{N}$ bond. It is formed from isomer 9 by a proton transfer from the -NH- group to the terminal oxygen atom. This tautomerization costs only $2 \mathrm{kcal} / \mathrm{mol}$, but the dipole moment decreases to 1.8 Debye. Two other isomers with a diazene bond were obtained close in energy to isomer 10 (isomer 12 and 13, both around $72 \mathrm{kcal} / \mathrm{mol}$ ). 
A\&A 589, A18 (2016)

Table 2. Computed relative stabilities $\Delta E(\mathrm{kcal} / \mathrm{mol})$ and dipole moments $\mu$ (Debye) of the lowest six energy isomers of urea at post HartreeFock levels of theory.

\begin{tabular}{|c|c|c|c|c|c|c|c|c|}
\hline \multirow{2}{*}{$\begin{array}{l}\text { Serial } \\
\#\end{array}$} & \multirow{2}{*}{$\begin{array}{l}\text { Isomer } \\
\text { structure }\end{array}$} & \multirow{2}{*}{$\begin{array}{l}\text { Point } \\
\text { group }\end{array}$} & \multicolumn{2}{|c|}{ MP2 } & \multicolumn{3}{|c|}{ CCSD } & \multirow{2}{*}{$\begin{array}{c}\operatorname{CCSD}(\mathrm{T}) \\
\Delta E\end{array}$} \\
\hline & & & $\Delta E$ & $\mu$ & $\Delta E$ & $\mu$ & $\mu_{\text {aug }}$ & \\
\hline 1 & & $C_{2}$ & 0.0 & 3.47 & 0.0 & 3.57 & 3.62 & 0.0 \\
\hline 1 ' & & $C_{\mathrm{s}}$ & 0.7 & 4.17 & 0.8 & 4.26 & 4.29 & 0.8 \\
\hline 2 & & $C_{1}$ & 15.1 & 2.27 & 14.7 & 2.29 & 2.30 & 14.5 \\
\hline 3 & & $C_{1}$ & 38.9 & 2.39 & 38.0 & 2.48 & 2.52 & 37.4 \\
\hline 4 & & $C_{\mathrm{s}}$ & 47.1 & 1.39 & 46.1 & 1.32 & 1.30 & 44.6 \\
\hline 5 & & $C_{1}$ & 57.4 & 1.85 & 55.8 & 1.88 & 1.90 & 54.4 \\
\hline 6 & & $C_{\mathrm{s}}$ & 59.9 & 1.73 & 57.1 & 1.74 & 1.74 & 55.7 \\
\hline
\end{tabular}

Notes. MP2/cc-pVTZ, CCSD/cc-pVTZ, and CCSD(T)/cc-pVTZ; $\mu_{\text {aug }}$ are ultimately refined values of the dipole moments at the CCSD/aug-ccPVTZ level. Colour code: $\mathrm{O}$ atoms in red; $\mathrm{H}$ atoms in white; $\mathrm{C}$ atoms in grey; $\mathrm{N}$ atoms in blue.

Table 3. Computed relative stabilities $\Delta E(\mathrm{kcal} / \mathrm{mol})$ and dipole moments $\mu$ (Debye) of the lowest six energy isomers of thiourea at post HartreeFock levels of theory.

\begin{tabular}{|c|c|c|c|c|c|c|c|c|}
\hline \multirow{2}{*}{$\begin{array}{l}\text { Serial } \\
\#\end{array}$} & \multirow{2}{*}{$\begin{array}{l}\text { Isomer } \\
\text { structure }\end{array}$} & \multirow{2}{*}{$\begin{array}{l}\text { Point } \\
\text { group }\end{array}$} & \multicolumn{2}{|c|}{ MP2 } & \multicolumn{3}{|c|}{ CCSD } & \multirow{2}{*}{$\begin{array}{c}\mathrm{CCSD}(\mathrm{T}) \\
\Delta E\end{array}$} \\
\hline & & & $\Delta E$ & $\mu$ & $\Delta E$ & $\mu$ & $\mu_{\text {aug }}$ & \\
\hline 1 & & $C_{2}$ & 0.0 & 4.62 & 0.0 & 4.71 & 4.63 & 0.0 \\
\hline 2 & & $C_{1}$ & 12.7 & 2.65 & 11.8 & 2.65 & 2.64 & 11.5 \\
\hline $3(5)$ & & $C_{1}$ & 24.4 & 2.52 & 23.2 & 2.58 & 2.57 & 22.5 \\
\hline $4(8)$ & & $C_{S}$ & 28.8 & 1.99 & 27.3 & 2.05 & 2.04 & 26.6 \\
\hline $5(7)$ & & $C_{1}$ & 29.9 & 2.86 & 27.5 & 2.90 & 2.90 & 27.5 \\
\hline $6(3)$ & & $C_{S}$ & 34.7 & 2.93 & 33.9 & 3.02 & 2.94 & 33.1 \\
\hline
\end{tabular}

Notes. MP2/cc-pVTZ, CCSD/cc-pVTZ, and CCSD(T)/cc-pVTZ; $\mu_{\text {aug }}$ are ultimately refined values of the dipole moments at the CCSD/aug-ccPVTZ level. Colour code: $\mathrm{S}$ atoms in yellow; $\mathrm{H}$ atoms in white; $\mathrm{C}$ atoms in grey; $\mathrm{N}$ atoms in blue. 
Isomer 11 , diaziridin-3-ol, at $71 \mathrm{kcal} / \mathrm{mol}$ on the energy scale, is the first cyclic species that can be formed. Similar relative energies were obtained for the first three-member ring of the formamide $(74 \mathrm{kcal} / \mathrm{mol})$ and acetamide $(73 \mathrm{kcal} / \mathrm{mol})$ families. Four other three-members cyclic molecules were found in 15th, $17 \mathrm{th}, 19 \mathrm{th}$, and $21 \mathrm{st}$ positions at $75,94,98$, and $120 \mathrm{kcal} / \mathrm{mol}$ above urea, respectively. Finally the four-members rings occupy the 20th and 22nd positions at energies higher than $100 \mathrm{kcal} / \mathrm{mol}$ on the energy scale.

The MP2/cc-pVTZ, CCSD/cc-pVTZ and $\operatorname{CCSD}(\mathrm{T}) / \mathrm{cc}-$ pVTZ calculations confirm the B3LYP/6-31(d,p) results, the relative stabilities of the first six isomers being unchanged. More quantitatively, the relative energy values differ by no more than $3.7 \mathrm{kcal} / \mathrm{mol}$ (MP2), $2.8 \mathrm{kcal} / \mathrm{mol}$ (CCSD), and $2.2 \mathrm{kcal} / \mathrm{mol}$ $(\mathrm{CCSD}(\mathrm{T}))$ from the B3LYP ones (Table 2). Also, the dipole moments obtained at the MP2/cc-pVTZ level are very close to the B3LYP ones (the differences being smaller than $0.1 \mathrm{De}-$ bye). Convergence is achieved at the CCSD level, as shown by the values obtained successively with the cc-pVTZ and aug-ccpVTZ basis.

\section{2. $\mathrm{CH}_{4} \mathrm{~N}_{2} \mathrm{~S}$ isomers}

The most stable species that can be built from the $\mathrm{CH}_{4} \mathrm{~N}_{2} \mathrm{~S}$ set of atoms have the same Lewis structures as in the case of the urea family with sulphur in the place of oxygen (Table 3 ). The most stable isomer is thiourea, $\left(\mathrm{NH}_{2}\right)_{2} \mathrm{CS}$, of $\mathrm{C}_{2}$ symmetry with a dipole moment of ( $\sim 4$ Debye), which makes it attractive for radio detection. The conformer of $C_{\mathrm{S}}$ symmetry is not an energy minimum, but instead a transition state on the concerted $\mathrm{C}-\mathrm{NH}_{2}$ rotation potential. It should also be noted that the dipole moment of thiourea is the largest among those of all its isomers, whereas it was not the case for urea (isomer 9 of urea with $\sim 4$ Debye was the most polar molecule).

The second isomer on the energy scale, carbamimidothioic acid, $\mathrm{HN}=\mathrm{CSH}-\mathrm{NH}_{2}$, is $11.5 \mathrm{kcal} / \mathrm{mol}$ above thiourea at the $\operatorname{CCSD}(\mathrm{T})$ level (15.4 at B3LYP), which is very much in line with the usual energy separation between tautomers. However, its smaller dipole moment compared to that of $\mathrm{HN}=\mathrm{COH}-\mathrm{NH}_{2}$, coupled to the energy difference to $\left(\mathrm{NH}_{2}\right)_{2} \mathrm{CS}$, does not make it an easy target. The energetic evolution of the others isomers of thiourea is dramatically different from those of urea: first because their energy does not exceed $75.0 \mathrm{kcal} / \mathrm{mol}$ with respect to $\left(\mathrm{NH}_{2}\right)_{2} \mathrm{CS}$ (the highest isomer of $\mathrm{CH}_{4} \mathrm{~N}_{2} \mathrm{O}$ molecules was $120 \mathrm{kcal} / \mathrm{mol}$ above urea); second because the order of isomers is rather dramatically changed, as illustrated in Table 3 where they are also referred according to the numbering of the urea structures given in parentheses.

The third isomer, $\mathrm{N}^{\prime}$-sulfanylmethanimidamide $\mathrm{HSN}=$ $\mathrm{CHNH}_{2}$, is only $22.5 \mathrm{kcal} / \mathrm{mol}$ above thiourea $(\sim 10 \mathrm{kcal} / \mathrm{mol}$ above the $\mathrm{HN}=\mathrm{CSH}-\mathrm{NH}_{2}$ enolic structure), whereas the relative energy of isomer 3 in the urea family (formohydrazide $\left.\mathrm{NH}_{2} \mathrm{NHCHO}\right)$ was $37 \mathrm{kcal} / \mathrm{mol}(\sim 20 \mathrm{kcal} / \mathrm{mol}$ above the $\mathrm{HN}=\mathrm{COH}-\mathrm{NH}_{2}$ enolic structure). It is also noteworthy that isomers 3 to 6 of thiourea are within a $\sim 10 \mathrm{kcal} / \mathrm{mol}$ energy range, instead of $\sim 20 \mathrm{kcal} / \mathrm{mol}$ for the urea family. This energetic proximity, together with dipole moments between 2 and 3 Debye and very close rotational constants due to similar U-shape structures of the heavy atoms connectivity, render a radio search very difficult in the present conditions.

\section{Discussion and concluding remarks}

From this exhaustive study of the relative energies of the compounds that can be formed from the $\mathrm{CH}_{4} \mathrm{~N}_{2} \mathrm{O}$ set of atoms, we found that there is no theoretical reason not to believe that the molecule observed towards the Sgr B2-LMH region during the multi-telescope campaign by Remijan et al. (2014) is not urea. Following the same reasoning, thiourea is the sulphur analogue molecule to search for.

Looking now at the complete manifolds of isomers that can be obtained from the $\mathrm{CH}_{4} \mathrm{ON}_{2}$ and $\mathrm{CH}_{4} \mathrm{SN}_{2}$ sets of atoms, we have linear backbones that lead to a wide variety of functional groups, (thio)amides, imines, hydrazides, diazenes, and (thio)alcools, as well as cyclic species. In the last case, we found diaziridines that contain two nitrogen atoms in a threemembered ring, oxaziridines (NCO cycles), or oxadiazetidine (four-member NNCO cycles). With at least two hetero atoms in the cycle, these cycles are higher in energy than most of the linear structures. As we showed above, species with the NCO/NCS connectivity, i.e. those possibly leading to prebiotic species, are the most stable ones (found mostly under $60 \mathrm{kcal} / \mathrm{mol}$ with respect to urea, under $45 \mathrm{kcal} / \mathrm{mol}$ with respect to thiourea), whereas compounds with $\mathrm{N}=\mathrm{O} / \mathrm{N}=\mathrm{S}$ bonds do not occur below $66 / 45 \mathrm{kcal} / \mathrm{mol}$, so barely lower than the first cyclic molecule in oxygen and sulphur families. These results agree with those obtained for formamide and acetamide by Lattelais et al. (2010).

More generally, it can be seen that the energy separation between thiourea and its higher energy isomers is more contracted than for the urea analogues. Only the iminol isomers that are relatively close to the most stable species might be subject to tentative observation, if one accepts the hypothesis by Tsipis \& Karapidis (2003) that these molecules are also stable intermediates in the syntheses of urea and thiourea. The energy differences between $\mathrm{HN}=\mathrm{COHNH}_{2}$ and $\left(\mathrm{NH}_{2}\right)_{2} \mathrm{CO}(14.5 \mathrm{kcal} / \mathrm{mol})$ and between $\mathrm{HN}=\mathrm{CSHNH}_{2}$ and $\left(\mathrm{NH}_{2}\right)_{2} \mathrm{CS}(11.5 \mathrm{kcal} / \mathrm{mol})$ are in the range of those found between $\mathrm{CH}_{3} \mathrm{CHO}$ and $\mathrm{CH}_{2} \mathrm{CHOH}$ and between $\mathrm{CH}_{3} \mathrm{CN}$ and $\mathrm{CH}_{2} \mathrm{CNH}$ : 10.3 and $27.1 \mathrm{kcal} / \mathrm{mol}$, respectively. Both tautomers have been identified in hot core regions with abundances ratios of $\mathrm{CH}_{3} \mathrm{CHO} / \mathrm{CH}_{2} \mathrm{CHOH} \sim 2-10$ (Turner \& Apponi 2001) and $\mathrm{CH}_{3} \mathrm{CN}$ and $\mathrm{CH}_{2} \mathrm{CNH} \sim 100$ (Lovas et al. 2006). Depending on these data, it can then be anticipated that the imino isomers should be between one and two orders of magnitude less abundant than urea/thiourea in the same hot core environment. All other isomers can hardly be considered as plausible candidates for detection in the ISM, because of their high energy with respect to urea and/or thiourea.

Accurate rotational constants have been determined in the laboratory for urea by Remijan et al. (2014) and for thiourea by Lesarri et al. (2004):

$$
\mathrm{A}=11233.3212 ; \mathrm{B}=10369.3727 ; \mathrm{C}=5416.632(\mathrm{MHz})
$$
and

$\mathrm{A}=10581.8159 ; \mathrm{B}=5143.31525 ; \mathrm{C}=3463.78724(\mathrm{MHz})$ for $\left(\mathrm{NH}_{2}\right)_{2} \mathrm{CO}$ and $\left(\mathrm{NH}_{2}\right)_{2} \mathrm{CS}$, respectively. Our corresponding calculated values (B3LYP/aug-cc-pVTZ) are

$$
\mathrm{A}=11235.08 ; \mathrm{B}=10353.41 ; \mathrm{C}=5426.64(\mathrm{MHz})
$$
and

$\mathrm{A}=10$ 584.59; $\mathrm{B}=5104.22 ; \mathrm{C}=3451.51(\mathrm{MHz})$.

But nothing is known for the enol isomers closeby, $\mathrm{HN}=\mathrm{COH}-\mathrm{NH}_{2}$ and $\mathrm{HN}=\mathrm{CSH}-\mathrm{NH}_{2}$, except the calculated values:

$$
\begin{aligned}
& \mathrm{A}=11181.38 ; \mathrm{B}=10472.88 ; \mathrm{C}=5422.37(\mathrm{MHz}) \\
& \text { and } \\
& \qquad \mathrm{A}=10446.64 ; \mathrm{B}=5050.11 ; \mathrm{C}=3411.05(\mathrm{MHz}) .
\end{aligned}
$$

To match the real rotational constants better, they have to be improved, which can be done using the following correction procedure. Taking the ratio of calculated to observed rotational 
constants for $\left(\mathrm{NH}_{2}\right)_{2} \mathrm{CO}$ as a scaling factor we estimate that the rotational constants of the enol isomer are

$$
\mathrm{A}=11 \text { 179.62; B = } 10489.03 ; \mathrm{C}=5412.37(\mathrm{MHz}) \text {. }
$$

The same approach applied to $\left(\mathrm{NH}_{2}\right)_{2} \mathrm{CS}$ leads to

$$
\mathrm{A}=10443.90 \mathrm{~B}=5088.79 ; \mathrm{C}=3423.19(\mathrm{MHz}) \text {. }
$$

These values should be accurate enough to initiate laboratory work before a search is undertaken in the ISM.

It is worth noting that our calculated dipole moment of urea (3.62 Debye) is close that of the 3.83 Debye found by Brown et al. (1975). It is oriented along the $\mathrm{C}=\mathrm{O}$ axis. Nonzero components of the dipole along the other inertial axis do not exist according to the $\mathrm{C}_{2 v}$ symmetry originally considered from the crystalline structure at the time when the microwave spectrum was recorded. Similar symmetry arguments apply to the most stable $\mathrm{C}_{2}$ conformer. By contrast, the $C_{\mathrm{s}}$ conformer, $\sim 0.8 \mathrm{kcal} / \mathrm{mol}$ above has a larger dipole of 4.29 Debye showing two components of 3.92 and 1.75 Debye along the $\mathrm{C}=\mathrm{O}$ axis and orthogonal to the $\mathrm{O}=\mathrm{C}(\mathrm{NN})$ heavy atoms plane, respectively.

Using the MEP as a tool for the hunt of interstellar complex organic molecules (Lattelais et al. 2010) is still controversial. Nevertheless, the recent actuality on the Rosetta/Philae mission to Comet 67P/Churyumov-Gerasimenko (hereafter 67P; Goesmann et al. 2015), showing that almost all the 16 molecules used to fit the COmetary Sampling And Composition (COSAC) mass spectrum satisfy the minimum energy criterion, including $\mathrm{CH}_{3} \mathrm{NCO}$, also detected in Sgr B2(N) (Halfen et al. 2015), provide clear support to the present study. In the same way, the recent identification of isocyanic acid, $\mathrm{HNCO}$ and formamide $\mathrm{NH}_{2} \mathrm{CHO}$ in low- and intermediate-mass prestellar and protostellar objects (López-Sepulcre et al. 2015) is another series of observations in agreement with the minimum energy criterion predictions.

However, it should be pointed out that among the 16 organic species identified on 67P, one finds several containing nitrogen but none containing sulphur. At that point, some reasons may be considered, the first one being the oxygen/sulphur abundance ratio, whose value is known to vary from one object to the other. The cosmic abundances inferred from the present-day solar photosphere by Asplund et al. (2009) lead to an $\mathrm{O} / \mathrm{S}$ ratio of $\sim 40$, whereas Lodders et al. (1975) obtained O/S of $\sim 20$ from the corresponding values for CI carbonaceous chondrites. Another way of estimating the relative abundances of sulphur to oxygen-bearing species, better suited to 67P, is to consider the observed abundance ratios for similar systems, such as $\mathrm{H}_{2} \mathrm{CO} / \mathrm{H}_{2} \mathrm{CS} \sim 55, \mathrm{CO}_{2} / \mathrm{CS}_{2} \sim 60$, and $\mathrm{CO} / \mathrm{CS} \sim 80$ in comet Hale-Bopp (Bockelée-Morvan et al. 2000). These values are in perfect agreement with the $\mathrm{O} / \mathrm{S}$ value of 55 recommended by Gilmour \& Sephton (2004) in their introduction to astrobiology.

Another point to consider in regard to the non-detection of sulphur containing compounds in comet 67P is the limitation of the COSAC instrument itself, i.e. the low resolution, meaning that single mass peaks cannot be resolved into different molecular species and that for mass/charge ratios $(\mathrm{m} / \mathrm{z})$ over 62 , the signals could not be extracted from the background noise (Goesmann et al. 2015). Nevertheless, the non-detection of compounds containing sulphur in these conditions does not mean that they do not exist in another environment like the ISM. It should be stressed that the minimum energy criterion is not applicable to $\left(\mathrm{NH}_{2}\right)_{2} \mathrm{CO} /\left(\mathrm{NH}_{2}\right)_{2} \mathrm{CS}$ since urea and thiourea are analogues and not isomers (they are not formed from the same atoms).

Comparison of molecular abondances between comets and the ISM has already been extensively discussed in the literature (Bockelée-Morvan et al. 2000) and showed that the abundances of S-bearing species are difficult to rationalize due to rapid gas-phase chemistry. In all events, one can anticipate that thio-urea should be one to two orders of magnitude less abundant than urea.

Even if we admit that the reason for the existence of MEP in space is not obvious, the observations discussed in this note, together with those of $\mathrm{CH}_{3} \mathrm{NCO}$ reported from the Rosetta/Philae mission and the Arizona Radio Observatory towards Sgr B2(N), are the most recent robust facts supporting that a minimum energy criterion can be used as such, at least "pragmatically". Finally, that the Wöhler synthesis has produced the most stable possible isomer is in agreement with the minimum energy principle. This is not only important from an epistemological point of view, but it suggests that the same principle might also be at work (at least partially) in astrobiology.

Acknowledgements. This work was supported by CNRS national programmes PCMI (Physics and Chemistry of the Interstellar Medium) and EPOV (Evolution of Planets and Origins of Life).

\section{References}

Asplund, M., Grevesse, N., Sauval, A. J., \& Scott, P. 2009, ARA\&A, 47, 481 Becke, A. D. 2000, J. Chem. Phys., 98, 5648

Bockelée-Morvan, D., Lis, D. C., Wink, J. E., et al. 2000, A\&A, 353, 1101

Bonchev, D., \& Rouvray, D. 1991, Chemical Graph Theory: Introduction and Fundamentals (New York, USA: Gordon and Breach Pub.)

Brown, R. D., Godfrey, P. D., \& Storey, J. 1975, J. Mol. Spectrosc., 58, 445

Dunning, T. 1989, J. Chem. Phys., 90, 1007

Duvernay, F., Chiavassa, T., Borget, F., \& Aycard, F. 2005, J. Phys. Chem. A, 109,6008

Fourikis, N., Sinclair, M. W., Robinson, B. J., Godfrey, P. D., \& Brown, R. D. 1974, Aust. J. Phys., 27, 425

Frisch, M., Trucks, G., Schlegel, et al. 2009, Gaussian 09, Revision A.02, Gaussian Inc., Wallingford CT

Garrod, R. T., Widicus Weaver, S. L., \& Herbst, E. 2008, ApJ, 682, 283

Gilmore, W., Morris, M., Palmer, P., et al. 1976, ApJ, 204, 43

Gilmour, I., \& Sephton, M. A. 2004, In An introduction to Astrobiology, eds. I. Gilmour, \& M. A. Sephton (Cambridge, UK: Cambridge University Press) Goesmann, W., Rosenbauer, M., Bredehöft, P., et al. 2015, Science, 349, 6247 Haldane, J. B. 1929, Rationalist Annual, 148

Halfen, D. T., Ilyushin, V. V., Ziurys, L. M., et al. 2015, ApJ, 812, L5

Hayatsu, R., Studier, M. H., Moore, L. P., \& Anders, E. 1975, Geochim. Cochim. Acta, 39, 471

Hollis, J. M., Lovas, F. J., \& Remijan, A. J. 2006, ApJ, 643, L25

Inostroza, N., \& Senent, M. L. 2012, Chem. Phys. Lett., 524, 25

Koch, W., \& Holthausen, M. C. 2001, A Chemist Guide to Density Functional Theory, 2nd edn. (Weinheim, Germany: Wiley-VCH)

Lattelais, M., Pauzat, F., Ellinger, Y., et al. 2009, ApJ, 696, L133

Lattelais, M., Pauzat, F., Ellinger, Y., \& Ceccarelli, C. 2010, A\&A, 519, A30

Lee, T. J., \& Scuseria, G. E. 1995, In Quantum mechanical electronic structure calculations with chemical accuracy, ed. S. R. Langhoff (Dordrecht: Kluwer Academic Publishers)

Lee, C., Yang, W., \& Parr, R. G. 1988, Phys. Rev. B, 37, 785

Lesarri, A., Mata, S., Blanco, S., Lopez, J. C., \& Alonso, J. 2004, J. Chem. Phys., 120,6191

Lodders, K., Palme, H., \& Gail, H. 2009, Abundances of the elements in the solar system. In Landolt Börnstein, New Series, Vol. VI/4B, Chap. 4.4, ed. J. E. Trümper (Berlin Heidelberg, New York: Springer Verlag), 560

Lopèz-Sepulcre, A., Jaber, A., Mendoza, B., et al. 2015, MNRAS, 449, 2438

Lovas, F. J., Hollis, J. M., Remijan, A. J., \& Jewell, P. R. 2006, ApJ, 645, L137

McKay, B. D., \& Piperno, A. 2014, J. Symbolic Comp., 60, 94

Miller, S. 1953, J. Amer. Chem. Soc., 77, 2351

Miller, S., \& Urey, H. C. 1959, Science, 130, 245

Raunier, S., Chiavassa, T., Duvernay, F., et al. 2004, A\&A, 416, 165

Remijan, A. J., Snyder, L. E., McGuire, B. A., et al. 2014, ApJ, 783, 77

Rouvray, D. H., 1974, Chem. Soc. Rev., 3, 355

Rubin, R. H., Swenson, Jr., G. W., Benson, R. C., Tigelaar, H. L., \& Flygare, W. H. 1971, ApJ, 169, L39

Szabo, A., \& Ostlund, N. S. 1996, Mod. Quant. Chem.: Introduction to advanced electronic structure theory (New York: Dover Publishing, Mineola)

Tsipis, C. A., \& Karapidis, P. A. 2003, J. Ame. Chem. Soc., 125, 2307

Turner, B. E., \& Apponi, A. J. 2001, ApJ, 561, L207

Wöhler, F. 1828, Ann. Phys. 88, 253 